\title{
İnsan Hakları Yurttaşık ve Demokrasi Ders Kitabının Okunabilirlik ve Yaş Düzeyine Uygunluk Açılarından Değerlendirilmesi
}

\author{
Cevat Eker ${ }^{1}$, Murat İnce ${ }^{1}$, Duygu Sağlam²
}

${ }^{1}$ Ĕ̆itim Bilimleri Bölümü, Ereğli Eğitim Fakültesi, Bülent Ecevit Üniversitesi, Zonguldak, Türkiye

${ }^{2}$ Yabancı Diller Yüksek Okulu, Bülent Ecevit Üniversitesi, Zonguldak, Türkiye

Sorumlu Yazar: Cevat Eker, cevateker@gmail.com

Makale Türü: Araştırma Makalesi

Kaynak Gösterimi: Eker, C., İnce, M., \& Sağlam, H. (2018). İnsan Hakları Yurttaşlık ve Demokrasi Ders Kitabının okunabilirlik ve yaş düzeyine uygunluk açılarından değerlendirilmesi Ĕgitimde Kuram ve Uygulama, 14(4), 404-416. doi:

10.17244/eku.414512

\section{Assessment of the Human Rights, Citizenship and Democracy Course Book for Readability and Age Level Compliance}

\author{
Cevat Eker ${ }^{1}$, Murat İnce ${ }^{1}$, Duygu Sağlam²
}

\section{${ }^{I}$ Department of Educational Sciences, Ereğli Faculty of Education, Bülent Ecevit University, Zonguldak, Turkey ${ }^{2}$ School of Foreign Languages, Bülent Ecevit University, Zonguldak, Turkey}

Corresponding Author: Cevat Eker, cevateker@gmail.com

Article Type: Research Article

To Cite This Article: Eker, C., İnce, M., \& Sağlam, H. (2018). İnsan Hakları Yurttaşlık ve Demokrasi Ders Kitabının okunabilirlik ve yaş düzeyine uygunluk açılarından değerlendirilmesi. Eğitimde Kuram ve Uygulama, 14(4), 404-416. doi: 10.17244/eku.414512 
2018, 14(4), 404-416

\title{
İnsan Hakları Yurttaşlık ve Demokrasi Ders Kitabının Okunabilirlik ve Yaş Düzeyine Uygunluk Açılarından Değerlendirilmesi
}

\author{
Cevat Eker ${ }^{1}$, Murat İnce ${ }^{1}$, Duygu Sağlam ${ }^{2}$

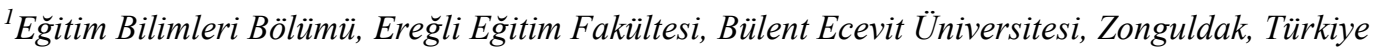 \\ ORCID: http://orcid.org/0000-0003-4215-1854 \\ ORCID: http://orcid.org/0000-0003-0557-0419 \\ ${ }^{2}$ Bülent Ecevit Üniversitesi, Yabancı Diller Yüksek Okulu, Zonguldak, Türkiye \\ ORCID: http://orcid.org/0000-0001-5619-6522
}

\begin{abstract}
Öz
$\mathrm{Bu}$ araştırmada İlkokul 4.sınıf İnsan Hakları, Yurttaşlık ve Demokrasi ders kitabının okunabilirlik ve yaş düzeyine uygunluk açılarından değerlendirilmesi amaçlanmıştır. Araştırma verilerine nitel araştırma yöntemlerinden doküman incelemesi yöntemiyle ulaşılmıştır. İncelenen doküman, 2017-2018 eğitim-öğretim yılında Milli Eğitim Bakanlığına bağlı okullarda okutulması önerilen ilkokul 4.sınıf 'İnsan Hakları, Yurttaşlık ve Demokrasi' ders kitabıdır. Araştırmanın amacına yönelik olarak her ünitenin konu içeriklerinden 100 kelimelik bilgi metinleri rastgele seçilmiş ve okunabilirlikleri FleschKincaid Formülü, Gunning Fog İndex ve Ateşman tarafından Türkçe için geliştirilen formüllere göre hesaplanmıştır. Araştırma sonucunda; İlkokul dördüncü sınıf İnsan Hakları, Yurttaşlık ve Demokrasi ders kitabındaki bilgi metinlerinin Flesch-Kincaid formülüne göre incelendiğinde çok zor olduğu ve okunabilirlik yaşının ise 25 ve üstü olduğu, Gunning Fog İndex formülüne göre okunabilirlik seviyesi açısından zor olduğu, Ateşman formülüne göre ders kitabının bilgi metinlerinin okunabilirlik seviyesi açısından birinci metnin çok zor; iki ve dördüncü metinlerin orta güçlükte; üç, beş ve altınc1 metinlerin ise zor olduğu, ders kitabının bilgi metinlerinin tümünün Felsch-Kincaid, Gunning Fog İndex ve Ateşman formüllerinin ortalamalarına göre zor olduğu sonucuna ulaşılmıștır. Elde edilen veriler doğrultusunda ilkokul dördüncü sınıf İnsan Hakları, Yurttaşlık ve Demokrasi ders kitabında yer alan bilgi metinlerinin öğrencilerin düzeyine uygun olmadığı söylenebilir. $\mathrm{Bu}$ sonuçlardan hareketle, ders kitaplarındaki okuma metinlerinin öğrencilerin yaş ve seviyelerine uygun olarak hazırlanmasına yönelik önerilerde bulunulmuştur.
\end{abstract}

Makale Bilgisi

Anahtar Kelimeler: Ders kitabı, Okunabilirlik, Yaş düzeyine Uygunluk

Makale Geçmişi:

Geliş: 11 Nisan 2018

Düzeltme: 03 Ekim 2018

Kabul: 05 Ekim 2018

Makale Türü: Araştırma Makalesi 


\section{Assessment of the Human Rights, Citizenship and Democracy Course Book for Readability and Age Level Compliance}

\begin{abstract}
In this research, it was aimed to evaluate the 4th grade primary school human rights, citizenship and democracy textbook in terms of readability and age level. The research data was obtained through the document review with qualitative research methods. The document examined is the 4th grade 'Human Rights, Citizenship and Democracy' textbook, which is recommended to be taught in schools affiliated to the Ministry of National Education in the 2017-2018 academic year. For the purpose of the study, 100 words of information texts were randomly selected from the subject contents of each unit and their readability was calculated according to the Flesch-Kincaid Formula, Gunning Fog Index and the formula of Ateşman for Turkish. As a result of the research, the information texts of the fourth grade primary school human rights, citizenship and democracy textbook are very difficult when examined according to the Flesch-Kincaid formula, and readability age is 25 or more; according to the Gunning Fog Index formula, it is difficult to read in terms of readability level; according to Ateşman formula, in terms of the readibility level, the first text is very difficult, the second and the fourth texts are moderately difficult, and the third, fifth and sixth texts are difficult. All of the texts of the course book are found difficult when the average of the Felsch-Kincaid, Gunning Fog Index and Ateşman formulas is taken. According to the obtained data, it can be said that the information texts in the fourth grade primary school human rights, citizenship and democracy textbook do not conform to the level of the students. In the light of these results, it is recommended the reading texts in the textbooks be developed in accordance with the age and level of the students.
\end{abstract}

Article Info

Keywords: Textbook, Readibility, Age level compliance

Article History:

Received: 11 April 2018

Revised: 03 October 2018

Accepted: 05 October 2018

Article Type: Research Article 


\section{Giriş}

Okuma, bilgi edinmeyi sağlayan en temel zihinsel süreçlerden birisidir. Okuma becerisinin edinilmesi, diş dünyay1 aile ve öğretmen desteğiyle tanıyan çocuğun artık kendi başına da bu süreci devam ettirebilmesini sağlamaktadır. Çocuk okumaya başladıktan sonra dış dünyayı tanıma ve kavramada daha bağımsız olur. Sever'e (2003, s. 17) göre, temel okuma-yazma becerisinin kazanılmaya başlandığı ilköğretim dönemindeki çocukların öğretimde karsılaştıkları metinler ve kitaplar, onların öğrenimlerinin ileriki aşamalarında okuma alışkanlığı edinmiş birer okur olarak yetişmelerinde önemli bir sorumluluk üstlenir.

Öğrenme öğretme süreci içinde, planlı eğitim uygulamalarında öğrencilerin neler öğreneceğini, öğretmenlerin neler öğreteceğini gösteren temel araçlardan birinin ders kitapları olduğu söylenebilir. Ders kitapları, öğrencinin yaş ve bilgi seviyesine uygun bilişsel ve duyuşsal becerilerle donatılmış zengin metinlerden oluşan, öğretim programlarının esas aldığı ilkeler doğrultusunda hazırlanan, ihtiva ettiği bilgileri öğrenciye aktaran basılı eğitim ve öğretim materyalleridir (Çiftçi, Çeçen \& Melanlıŏlu, 2007). Ders kitaplarında yer alan bir metnin öğrencinin seviyesine uygun olup olmadığını ortaya koyan ölçütlerden biride "okunabilirlik" olarak adlandırılmaktadır. Atesman'a (1997) göre okunabilirlik, okuyan tarafından metinlerin kolay ya da zor anlaş1lır olma durumudur. Okunabilirlik, metinlerin cümle ve kelime uzunlukları ve bilinmeyen kelime sayısı göz önüne alınarak metnin güçlüğünü belirlemeyi amaçlar. Metinlerin güçlük düzeylerinin belirlenmesi metnin hangi düzeydeki okuyucuya uygun olduğunu, metin okuyucuya ulaşmadan önce belirlemeyi amaçlamaktadır.

Milli Eğitim Bakanlığı ders kitaplarının hazırlanmasına dair 12.09.2012 tarih ve 28409 sayılı yönetmelikte yer alan Milli Eğitim Bakanlığı Ders Kitapları ve Eğitim Araçları Yönetmeliği’nde, hazırlanacak ders kitabının aşağıdaki hususlara göre hazırlanması gerektiği belirtilmektedir. Bunlar;

a) İçerik;

1) Dersin eğitim ve öğretim programını kapsayacak şekilde düzenlenir.

2) Dersin özelliğine göre ünite, bölüm, tema ve konular arasında hacim bakımından eğitim ve öğretim programının içeriğine uygun bir denge kurulur.

b) Dil, anlatım ve üslup;

1) Yaşayan Türkçe doğru, güzel ve etkili kullanılır.

2) Konuların işlenişinde öğrencinin seviyesine ve gelişim özelliklerine uygun olarak doğru, anlaşılır, yalın bir dil ve anlatım kullanılır.

3) Dilin kullanımında, Türk Dil Kurumunun güncel Türkçe Sözlük ve Yazım Kılavuzu esas alınır.

c) Öğrenme, öğretme, ölçme ve değerlendirme;

1) Öğrenme yöntemleri ve stratejileri dikkate alınır ve üst düzey düşünme becerileri geliştirilir

2) Değerlendirmeye ilişkin unsurlar, ölçme ve değerlendirmenin ilke ve teknikleri dikkate alınarak düzenlenir.

ç) Teknik, tasarım ve düzenleme;

1) Görsel ve içerik tasarımı, öğrenmeyi destekleyecek nitelikte ve öğrencilerin gelişim özelliklerini dikkate alarak yapılır.

Okunup anlaşı1ması gerekli olan derslerden biride, İnsan Hakları, Yurttaşlık ve Demokrasi dersi gelmektedir. Bu sebeple Talim ve Terbiye Kurulu 25.06.2012 tarih ve 69 sayılı karar ile 2015-2016 öğretim yılından itibaren, ilköğretim 4. sınıflarda "İnsan Hakları, Yurttaşlık ve Demokrasi” dersi programının uygulanmasına karar verilmiştir. Bu derste,öğrencilere kavramsal bilginin öğretilmesinin yanında; insan hakları, yurttaşlık ve demokrasi ile ilgili temel değerlerin kazandırılması amaçlamaktadır. Dersin bir diğer amacı da öğrencilerin bu bilgi ve değerleri bir yaşam biçimi ve kültür hâline getirmelerini sağlamaktır. Böylelikle öğrenciler haklarını öğrenecek ve gerektiğinde talep edecekler, bunlara ilişkin etik değerlendirme yapabileceklerdir. İnsan hakları, yurttaşlık ve demokrasi dersi metinlerinde doğası gereği, oldukça fazla teknik terimler kullanılmaktadır. Bu durum ders kitabında yer alan metinlerin öğrenciler tarafından anlaşılmasını zorlaştırabilir. Bu yüzden okunabilirlik bu dersin kitaplarının seçiminde büyük bir önem kazanmaktadır.

Türkiye'de okunabilirlik ve yaş düzeyine uygunluk ile ilgili birçok araştırma (Kaya, 1998; Temur, 2002; Zorbaz, 2007; Köse,2009; Çetinkaya, 2010; Geçit, 2010; Güven,2010; Yürümez, 2010; Çeçen \& Aydemir, 2011; Karatay, Bolat \& Güngör, 2013; Okur \& Ar1, 2013; Baş \& Yıldız, 2015) yapılmıştır. İnsan Hakları, Yurttaşlık ve Demokrasi ders kitabın okunabilirliği ve yaş düzeyine uygunluğuna ilişkin bir çalışmanın yapılmadığı görülmüştür. Eğitim araçları arasında özel bir yere sahip olan, İnsan Hakları, Yurttaşlık ve Demokrasi ders kitabından öğrencilerin 
tam ve istenilen düzeyde yararlanabilmeleri için okunabilirlik düzeylerinin öğrencinin yaş seviyesine uygun olması önemlidir.

$\mathrm{Bu}$ önem doğrultusunda çalışmanın amacı, İlkokul 4. sınıf "İnsan Hakları, Yurttaşlık ve Demokrasi” ders kitabındaki bilgi metinlerinin okunabilirliğini ve yaş düzeyine uygunluğunu belirlemektir. Bu amaç doğrultusunda aşağıdaki alt problemlere cevap aranmıştır.

1. İlkokul dördüncü sınıf İnsan Hakları, Yurttaşlık ve Demokrasi ders kitabındaki metinlerin Flesch-Kincaid formülüne göre okunabilirlik düzeyi (kolay okunma) ve okunabilirlik yaşı nedir?

2. İlkokul dördüncü sınıf İnsan Hakları, Yurttaşlık ve Demokrasi ders kitabındaki metinlerin Gunning Fog İndeks formülüne göre okunma seviyeleri nedir?

3. İlkokul dördüncü sınıf İnsan Hakları, Yurttaşlık ve Demokrasi ders kitabındaki metinlerin Ateşman Formülüne göre okunabilirlik düzeyleri nedir?

4. İlkokul dördüncü sınıf İnsan Hakları, Yurttaşlık ve Demokrasi ders kitabındaki tüm metinlerin FleschKincaid, Gunning Fog İndeks ve Ateşman formüllerine göre ortalama okunabilirlik düzeyleri nedir?

\section{Yöntem}

\section{Araştırma Tasarımı}

$\mathrm{Bu}$ çalışmada nitel veri toplama yöntemlerinden doküman incelemesi tekniği kullanılmıştır. Doküman incelemesi, araştırılması amaçlanan olgu veya olgular hakkında bilgi içeren materyallerin analizini kapsar. Nitel araştırmalarda doküman incelemesi tek başına bir veri toplama yöntemi olabileceği gibi diğer veri toplama yöntemleri ile birlikte de kullanılabilir (Yıldırım \& Şimşek, 2016).

\section{Araştırmanın Veri Kaynağı}

Bu araştırmada, 2017-2018 eğitim öğretim yılı için Milli Eğitim Bakanlığı Talim ve Terbiye Kurulunun 14.06.2017 gün ve 8982336 sayılı yazısı ile eğitim aracı olarak kabul edilip dağıtılan ilkokul 4. sınıf ‘İnsan Hakları, Yurttaşlık ve Demokrasi' (Altay, Ertek, Polat, Selmanoğlu \& Yalçın, 2017) ders kitabının okunabilirlik düzeyi incelenmiştir. Ders kitabı 'İnsan Olmak', 'Hak, Özgürlük ve Sorumluluk', 'Adalet ve Eşitlik', 'Uzlaşı', 'Kurallar' ve 'Birlikte Yaşama' olmak üzere altı üniteden oluşmaktadır. Çalışmanın amacına yönelik olarak her ünitenin konu içeriklerinden 100 kelimeden oluşan bilgi metinleri araştırmacılar tarafından rastgele seçilmiş ve okunabilirlikleri Flesch-Kincaid Formülü, Gunning Fog İndeks ve Ateşman tarafından Türkçe için geliştirilen formüllere göre hesaplanmıştır.

\section{Veri Toplama Araçları}

Metinlerin güçlük düzeylerinin belirlenmesi amacıyla çeşitli okunabilirlik formülleri geliştirilmiştir. Aşağıda kısaca açıklanan bu formüller, metnin hangi düzeydeki okuyucuya uygun olduğunu, metin okuyucuya ulaşmadan önce kestirmeyi amaçlamaktadır.

Bugüne kadar çeşitli ülkelerde geliştirilen okunabilirlik formülleri kısaca su şekilde ele alınabilir:

Flesch-Kincaid Formülü: Seçilen metin örneklerinden gerekli bilgilere ulaşılmış, aşağıdaki formüle göre sayısal veriler yerlerine konmuş ve metinlerdeki okunabilirlik hesaplanmıştır.

1. Tüm metindeki hece sayıs1

2. Tüm metindeki cümle sayısı

3. Ortalama cümle uzunluğu (L): Yüz kelimenin metindeki cümle sayısına bölünmesi ile elde edilmektedir.

4. Kelime uzunluğu $(\mathrm{N})$ : Tüm metindeki toplam hece sayısının 100 kelimeye bölünmesi ile elde edilmektedir.

5. Flesch-Kincaid Formülüne göre okunabilirlik seviyesi (kolay okunma) aşağıdaki formüle göre elde edilmektedir.

Okunabilirlik seviyesi $=(\mathrm{L} \times 0,39)+(\mathrm{N} \times 11,8)-15.59$

6. Metinlerin okunabilirlik yaşı aşağıdaki formüle göre elde edilmektedir.

Okunabilirlik yaşı $=(\mathrm{L}$ x 0,39$)+(\mathrm{N}$ x 11,8) $-10,59$

7. Her üniteden alınan örnek metinlerden elde edilen okunabilirlik seviyelerinin ortalaması alınarak kitabın toplam olarak okunabilirliği tespit edilmektedir. Aynı yöntemle okunabilirlik yaşı da hesaplanmaktadır (Yürümez, 2010). Flesch-Kincaid formülünün kriterleri tablo l' de verilmiştir. 
Tablo 1. Flesch-Kincaid formülüne göre okunabilirlik düzeyleri (Karatay, vd. 2013)

\begin{tabular}{lcccc}
\hline \multicolumn{1}{c}{ Metnin Düzeyi } & $\begin{array}{c}\text { Ortalama Cümle } \\
\text { Uzunluğu }\end{array}$ & $\begin{array}{c}\text { Ortalama Hece } \\
\text { Sayısı }\end{array}$ & $\begin{array}{c}\text { Metnin Düzeyi } \\
\text { (sayısal olarak) }\end{array}$ & Tahmini Seviye \\
\hline 1.Çok kolay & 8 ve daha az & 123 ve daha az & $90-100$ & \\
2.Kolay & 11 & 131 & $80-90$ & 5. \\
3.Oldukça kolay & 14 & 139 & $70-80$ & 6. \\
4.Standart & 17 & 147 & $60-70$ & 7. \\
5.Oldukça zor & 21 & 155 & $50-60$ & $10 ., 9$. \\
6.Zor & 25 & 167 & $30-50$ & $13 ., 16$ \\
7.Çok zor & $29+$ & $192+$ & $0-30$ & Yetişkinler \\
\hline
\end{tabular}

Tablo 1 incelendiğinde, flesch-kincaid formülü uygulandıktan sonra elde edilen sayısal verilere göre, yüz kelimenin metindeki cümle sayısına bölünmesi ile elde edilen ortalama cümle uzunluğu, 8 ve daha az olarak bulunduğunda metnin düzeyinin çok kolay olduğu; bu rakamın yükselmesiyle birlikte zorluk derecesinin de yükseldiği sonucuna ulaşılmaktadır. Seçilen yüz kelimelik metinlerdeki hece sayılarının ortalamalarından elde edilen değer 123 ve daha az ise kullanılan metinlerin çok kolay; bu değerin artmasılyla doğru orantılı olarak metinlerin zorluk derecesinin de arttığı sonucuna ulaşılmaktadır. Flesch-kincaid okunabilirlik seviyesi hesabı yapıldıktan sonra elde edilen değer metnin sayısal olarak düzeyini sunmakta ve bu değerin 90-100 arası olması çok kolay olduğu; bu rakamın düşmesiyle ters orantılı olarak zorluk derecesinin de arttığı sonucuna ulaşılmaktadır. Son olarak, tablo.1'de belirtilen tahmini seviye bölümü ise flesch-kincaid formülünün yaş hesaplaması yapıldığında elde edilen değer hitap edilen yaş aralığını göstermektedir. Tablo.1'deki kriter kullanılarak Flesch-kincaid formülü uygulanan metinler yorumlanabilir.

Gunning Fog İndeks: Seçilen metin örneklerinden gerekli bilgilere ulaşılmış, aşağıdaki formüle göre sayısal veriler yerlerine konmuş ve metinlerdeki okunabilirlik hesaplanmıştır.

1. Yüz kelimelik metindeki cümle sayısı belirlenmektedir.

2. Ortalama cümle uzunluğu $(\mathrm{L})=$ kelime sayısının cümle sayısına bölümü ile hesaplanmaktadır.

3. Her metindeki üç ve üçten fazla heceli sözcüklerin sayısı bulunmuştur $(\mathrm{N})$.

4. Kolay okunma seviyesi aşağıdaki formül kullanılarak hesap edilmiştir.

Metnin okunma seviyesi $=(\mathrm{L}+\mathrm{N}) \times 0,4$

5. Her üniteden alınan örnek metinlerden elde edilen okunabilirlik seviyelerinin ortalaması alınarak kitabın toplam olarak okunabilirliği tespit edilmektedir. Aynı yöntemle okunabilirlik yaşı da hesaplanmaktadır (Yürümez, 2010).

Gunning Fog-indeks kriterlerine göre elde edilen sonuç, 3-11 arasında ise metnin anlaşılabilir olduğu, 12-14 arasında ise metnin fazla uzun olduğu, 15'ten yukarıda ise metnin hukuk diline yakın zor anlaşılabilir olduğu sonucuna varılmıştır (Sönmez, 2003).

Ateşman Formülü: Seçilen metin örneklerinden gerekli bilgilere ulaşılmış, aşağıdaki formüle göre sayısal veriler yerlerine konmuş ve metinlerdeki okunabilirlik hesaplanmıştır.

Okunabilirlik sayısı $=198,825-40,175 \times$ A $-2,610 \times$ B

$\mathrm{A}=$ Hece olarak ortalama kelime uzunluğu ( toplam hece / toplam kelime )

$\mathrm{B}=$ Kelime olarak ortalama cümle uzunluğu ( toplam kelime / toplam cümle )

Ateşman formülü'nün kriterlerine göre, Ateşman'ın formülüne göre belirlenmiş ortalama kelime ve cümle uzunlukları aşağıdaki tablo. 2 de belirtilmektedir.

Tablo 2. Ateşman'ın formülüne göre belirlenmiş kelime ve cümle ortalamaları

\begin{tabular}{lcc}
\hline & Hece olarak ort. Kelime uzunluğu & Kelime olarak ort. Cümle uzunluğu \\
\hline 1.En kolay metin & 2.2 & 4 \\
2.En zor metin & 3.0 & 30 \\
\hline
\end{tabular}


Tablo 2 incelendiğinde, Ateşman formülüne göre bir metindeki toplam hece sayısının metnin toplam kelime sayısına bölünmesiyle elde edilen 'hece olarak ortalama kelime uzunluğu' en kolay metinde 2.2 olarak; en zor metinde ise 3.0 olarak bulunmaktadır. Bir metindeki toplam kelime sayısının, metnin toplam cümle sayısına bölünmesiyle elde edilen 'kelime olarak ortalama cümle uzunluğu' ise en kolay metinde 4; en zor metinde 30 olarak bulunmaktadır. Tablo.2'deki kriter kullanılarak Ateşman formülü uygulanan metinler yorumlanabilir.

Tablo 3. Ateşman formülü metinlerin okunabilirlik aralıkları (Karatay, vd. 2013)

\begin{tabular}{lcc}
\hline & Düzey & Okunabilirlik Aralı̆̆ \\
\hline 1.Çok kolay & & $90-100$ \\
2.Kolay & $70-89$ \\
3.Orta güçlükte & $50-69$ \\
4.Zor & $30-49$ \\
5.Çok zor & $1-29$ \\
\hline
\end{tabular}

Tablo 3 incelendiğinde, Ateşman formülü metinlere uygulandığında metnin okunabilirlik düzeyleri 100'e yakınlaştıkça kolay, 0’a yaklaştıkça zor bir metin olduğu anlaşılmaktadır.

\section{Bulgular}

Bu bölümde araştırma verileri doğrultusunda, araştırmanın alt problemlerine ilişkin bulgular yer almaktadır.

\section{Birinci alt probleme ilişkin bulgular ve yorum}

Araştırmanın birinci alt problemi "İlkokul dördüncü sınıf İnsan Hakları, Yurttaşlık ve Demokrasi ders kitabındaki metinlerin Flesch-Kincaid formülüne göre okunabilirlik düzeyi (kolay okunma) ve okunabilirlik yaşı nasıldır?" şeklinde ifade edilmişti. Bu alt probleme bağlı olarak elde edilen bulgular Tablo 4’te verilmiştir.

Tablo 4. Flesch-Kincaid formülüne göre incelenen ders kitabına ait veriler

\begin{tabular}{|c|c|c|c|c|c|c|c|}
\hline Metin & 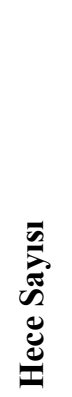 & 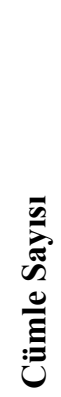 & 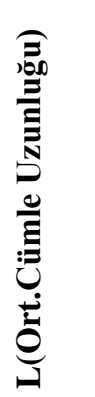 & 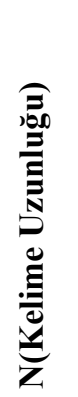 & 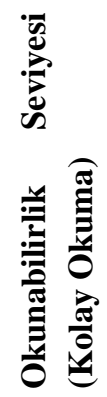 & 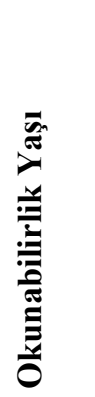 & 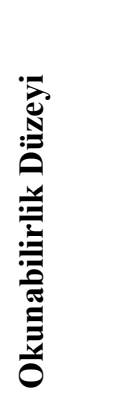 \\
\hline 1.Doğuştan Gelen Haklarımız & 275 & 10 & 10 & 2,75 & 20,76 & 25,76 & Çok zor \\
\hline 2.Birlikte Yaşama Kültürü & 286 & 9 & 11,11 & 2,86 & 29,26 & 27,49 & Çok zor \\
\hline 3.Adalet ve Eşitlik & 300 & 8 & 12,5 & 3 & 24,68 & 29,68 & Çok zor \\
\hline 4.Anlaşmazlıkların Nedenleri & 299 & 10 & 10 & 2,99 & 23,59 & 28,59 & Çok zor \\
\hline 5.Kurallar ve Toplumsal Ahenk & 319 & 9 & 11,11 & 3,19 & 26,07 & 31,38 & Çok zor \\
\hline 6.Düzenleyici Kurumlar & 313 & 9 & 11,11 & 3,13 & 25,67 & 30,67 & Çok zor \\
\hline
\end{tabular}

Tablo 4 incelendiğinde, flesch-kincaid formülüne göre ilkokul dördüncü sınıf insan hakları, yurttaşl1k ve demokrasi ders kitabının bilgi metinlerinin ortalama cümle uzunlukları sınıf seviyesine uygun olduğu, fakat ortalama hece sayısı ve okunabilirlik seviyesi açılarından ise, çok zor olduğu, okunabilirlik yaşının ise 25-31 yaş aralığında olduğu yani ilkokul dördüncü sınıfa göre okunabilirliğinin çok zor olduğu sonucuna ulaşılmıştır. Bu sonucun, kullanılan kelimelerin zorluğundan kaynaklanmış olabileceği düşünülmektedir. 


\section{İkinci alt probleme ilişkin bulgular ve yorum}

Araştırmanın ikinci alt problemi "İlkokul dördüncü sınıf İnsan Hakları, Yurttaşlık ve Demokrasi ders kitabındaki metinlerin Gunning Fog İndeks formülüne göre okunma seviyesi nasıldır?” şeklinde ifade edilmişti. Bu alt probleme bağlı olarak elde edilen bulgular Tablo. 5’te verilmiştir.

Tablo 5. Gunning Fog İndeks formülüne göre incelenen ders kitabına ait veriler

\begin{tabular}{|c|c|c|c|c|c|}
\hline Metin & 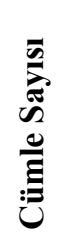 & 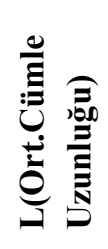 & 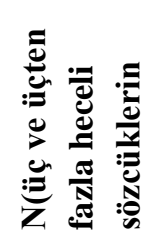 & 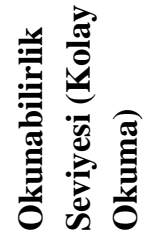 & 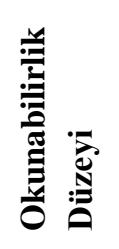 \\
\hline 1.Doğuştan Gelen Haklarımız & 10 & 10 & 52 & 24,8 & Çok zor \\
\hline 2.Birlikte Yaşama Kültürü & 9 & 11,11 & 61 & 28,84 & Çok zor \\
\hline 3.Adalet ve Eşitlik & 8 & 12,8 & 64 & 30,6 & Çok zor \\
\hline 4.Anlaşmazlıkların Nedenleri & 10 & 10 & 54 & 25,6 & Çok zor \\
\hline 5.Kurallar ve Toplumsal Ahenk & 9 & 11,11 & 69 & 32,04 & Çok zor \\
\hline 6.Düzenleyici Kurumlar & 9 & 11,11 & 64 & 30,04 & Çok zor \\
\hline
\end{tabular}

Tablo 5 incelendiğinde, gunning fog index formülüne göre ilkokul dördüncü sınıf İnsan Hakları, Yurttaşlık ve Demokrasi ders kitabının bilgi metinlerinin okunabilirlik seviyesi açısından zor olduğu sonucuna ulaşılmıştır. Bu sonucun kullanılan sözcüklerin zor ve anlaşılmaz olduğu, hukuk diline yakın olduğundan kaynaklandığı düşünülmektedir.

\section{Üçüncü alt probleme ilişkin bulgular ve yorum}

Araştırmanın üçüncü alt problemi "İlkokul dördüncü sınıf İnsan Hakları, Yurttaşlık ve Demokrasi ders kitabındaki metinlerin Ateşman Formülüne göre okunabilirlik düzeyleri nasıldır?" şeklinde ifade edilmişti. Bu alt probleme bağlı olarak elde edilen bulgular Tablo 6'da verilmiştir.

Tablo 6. Ateşman formülüne göre incelenen ders kitabına ait verileri

\begin{tabular}{|c|c|c|c|c|}
\hline Metin & 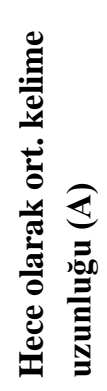 & 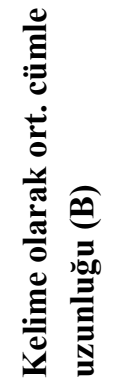 & 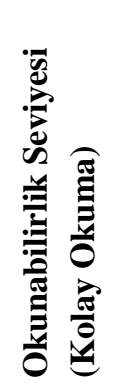 & 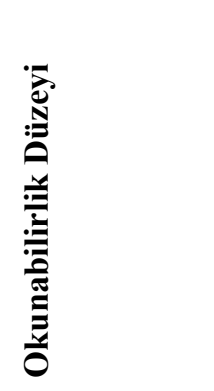 \\
\hline 1.Doğuştan Gelen Haklarımız & 2,75 & 10 & 26,1 & Çok zor \\
\hline 2.Birlikte Yaşama Kültürü & 2,86 & 11,11 & 54,92 & Orta Güçlükte \\
\hline 3.Adalet ve Eşitlik & 3 & 12,5 & 45,67 & Zor \\
\hline 4.Anlaşmazlıkların Nedenleri & 2,99 & 10 & 52,60 & Orta Güçlükte \\
\hline 5.Kurallar ve Toplumsal Ahenk & 3,19 & 11,11 & 41,66 & Zor \\
\hline 6.Düzenleyici Kurumlar & 3,13 & 11,11 & 44,07 & Zor \\
\hline
\end{tabular}

Tablo 6 incelendiğinde, Ateşman formülüne göre ders kitabının bilgi metinlerinin hece olarak ortalama kelime uzunlukları açısından zor olduğu fakat kelime olarak ortalama cümle uzunluğuna bakıldığında kolaya yakın oldukları, okunabilirlik seviyesi açısından ise birinci metnin çok zor; iki ve dördüncü metinlerin orta güçlükte; üç, beş ve altınc1 metinlerin ise zor olduğu sonucuna ulaşılmıştır. Bu durumun kelime ve cümlelerin uzunluğundan kaynaklandığı düşünülmektedir. 


\section{Dördüncü alt probleme ilişkin bulgular ve yorum}

Araştırmanın dördüncü alt problemi "İlkokul dördüncü sınıf insan hakları, yurttaşlık ve demokrasi ders kitabındaki tüm metinlerin Flesch-Kincaid, Gunning Fog İndeks ve Ateşman formüllerine göre ortalama okunabilirlik düzeyleri nasıldır?” şeklinde ifade edilmişti. Bu alt probleme bağlı olarak elde edilen bulgular Tablo. 7'de verilmiştir.

Tablo 7. Flesch-Kincaid, Gunning Fog İndex ve Ateşman formüllerine göre incelenen tüm metinlerin ortalama okunabilirlik seviyeleri

\begin{tabular}{lccc}
\hline & Flesch-Kincaid & Gunning Fog İndex & Ateşman \\
\hline $\begin{array}{l}\text { Tüm metinlerin Ortalama } \\
\text { Okunabilirlik Seviyeleri }\end{array}$ & 25,005 & 28,65 & 44,17 \\
\hline
\end{tabular}

Tablo 7 incelendiğinde, ders kitabında yer alan bilgi metinlerinin tümünün felsch-kincaid, gunning fog index ve Ateşman formüllerine göre zor olduğu sonucuna ulaşılmıştır.

Araştırma sonucunda elde edilen veriler doğrultusunda ilkokul dördüncü sınıf insan hakları, yurttaşlık ve demokrasi ders kitabındaki bilgi metinlerinin öğrencilerin düzeyine uygun olmadığı söylenebilir.

\section{Tartışma, Sonuç ve Öneriler}

İlkokul 4.sınıf İnsan Hakları, Yurttaşlık ve Demokrasi ders kitabındaki bilgi metinlerinin okunabilirliğini ve yaş düzeyini belirlemek için yapılan bu araştırmada, aşağıdaki sonuç elde edilmiştir:

1. İlkokul dördüncü sınıf insan hakları, yurttaşlık ve demokrasi ders kitabındaki bilgi metinlerinin FleschKincaid formülüne göre incelendiğinde çok zor olduğu ve okunabilirlik yaşının ise 25-31 yaş aralı̆̆ında olduğu sonucuna ulaşı1mıştır.

2. Gunning Fog İndex formülüne göre okunabilirlik seviyesi açısından zor olduğu sonucuna ulaşılmıştır.

3. Ateşman formülüne göre ders kitabının bilgi metinlerinin okunabilirlik seviyesi açısından birinci metnin çok zor; iki ve dördüncü metinlerin orta güçlükte; üç, beş ve altıncı metinlerin ise zor olduğu sonucuna ulaşılmıştır.

4. Ders kitabının bilgi metinlerinin tümünün Felsch-Kincaid, Gunning Fog İndex ve Ateşman formüllerinin ortalamalarına göre zor olduğu sonucuna varılmıştır.

Araştırmada elde edilen sonuçlar doğrultusunda ilkokul dördüncü sınıf insan hakları, yurttaşlık ve demokrasi ders kitabının bilgi metinlerinin okunabilirlik düzeylerinin zor olduğu ve 4. Sınıf öğrencilerinin yaşlarına uygun olmadığı sonucuna ulaşılmıştır. Bu sonucu destekler nitelikte araştırmalarda yapılmıştır. Örneğin, Çiftçi, Çeçen ve Melanlıoğlu (2007) Ateşman formülünü kullanarak Türkçe ders kitaplarının okunabilirlik açısından incelendiği araştımada, bilgilendirici metinlerin öyküleyici metinlere göre daha düşük okunabilirlik puanına sahip olduklarını belirtmişlerdir. Bir kitabın okunabilir olması, yazarın aktarmak istediklerinin okuyucu tarafından anlaşılabilmesine bağlıdır. Öğrenciler kısa ve sade yazılmış cümleleri, uzun ve karmaşık yazılmış cümlelere göre daha kolay anlamaktadır. Benzer bir araştırmada, Bağcı ve Ünal (2013) ders kitaplarındaki metinlerin okunabilirlik düzeyinin düşük olduğu sonucuna ulaşmışlardır.

Araştırmanın sonuçlarına benzer nitelikte sonuçları ortaya koyan çalışmalardan biri de Yürümez (2010) tarafından yapılmıştır. Çalışmada Milli Eğitim Bakanlığı tarafından hazırlanan ortaöğretim 9. sınıf biyoloji ders kitabının okunabilirliğini ve hedef yaş düzeyine uygunluğunu belirlemeyi amaçlamıştır. Flesch-Kincaid ve Gunning Fog İndex formüllerini içeren çeşitli formüllerle incelenen kitabın zor anlaş1lır bir dile sahip olduğu ve hedef yaşa uygun olmadığı sonucuna ulaşmıştır. Güven (2010) ise yaptığı benzer bir çalışmada, ilköğretim 6. sınıf fen ve teknoloji ders kitabının okunabilirliği ve hedef yas düzeyine uygunluğunu araştırmıştır. Ders kitabını Flesch-Kincaid, Gunning Fog İndex, Cloze Test ve Sönmez formüllerine göre incelemiş ve Flesch-Kincaid ve Gunning Fog İndex formüllerine göre kitabın anlaşılmasının zor olduğunu belirtmiştir. Karatay, ve diğerleri (2013) yaptıkları çalışmalarında, Türkçe ders kitaplarına alınan metinlerin uzman görüşü ve çıkartmalı okunabilirlik işlemine göre okunabilirlik ve anlaşılabilirliklerini incelemişlerdir. Flesch-Kincaid, Gunning Fog İndex ve Ateşman'ın da içinde 
bulunduğu okunabilirlik formüllerine göre Türkçe ders kitaplarındaki metinlerin genel olarak zor olduğu sonucuna varılmıştır. Bir kitabın kolay okunma seviyesi kurulan cümlelerin uzunluğuna, kısalığına, kullanılan kelimelerin karmaşıklı̆̆ına ve sadeliğine bağlıdır (Soyibo, 1996). Yapılan araştırmalar incelendiğinde, okullarda okutulması amaçlanan ders kitaplarının hazırlanmasında içerikte bulunan metinlerin seviyeleri ve öğrencilerin yaşları, okuma düzeyleri gibi önemli özelliklerin dikkate alınmadan hazırlandığı söylenebilir.

Araştırmada elde edilen sonuçlar doğrultusunda, şu öneriler verilebilir;

Öğrenme-öğretme sürecinde esas olan öğrencinin dersi algılayıp içselleştirmesidir. Bunda önemli olan etkenlerden biri, ders materyalleri olan kitapların anlaşılabilmesidir. Bu amaçla, ders kitaplarındaki metinler hedef kitlenin özelliklerine göre düzenlenmelidir.

Ders kitaplarının öğrencilerin yaş ve seviyelerine uygun hazırlanması anlaşılabilirlik açısından önemlidir. Bu nedenle, hazırlanan kitaplardaki metinlerin okunabilirlik düzeyleri kitaplar okutulmaya başlanmadan önce araştırılmalıdır. 


\section{Extended Summary}

\section{Introduction}

Reading is one of the most basic mental processes that provide information. Acquisition of reading skills allows the child, who knows the outside world with family and teacher support, to continue this process on their own. Once the child begins to read, he becomes more independent in recognition and conceptualization of the external world. According to Sever (2003, s. 17), during the primary school period in which the basic literacy skills start to be acquired, the texts and the books children are confronted with have an important responsibility to educate readers who have acquired good reading habits by the later stages of their studies.

Textbooks constitute the basic material of teaching. Textbooks are printed education and teaching materials which are made up of rich texts equipped for cognitive and affective skills appropriate to the age and level of the learners, prepared in line with the principles of the curriculum and for transferring information to the students (Çiftçi, Çeçen \& Melanlığlu, 2007). One of the criteria that indicates whether a text in course books is appropriate to the level of the student is called "Readability". According to Atesman (1997), readability is whether the text is easy or hard to understand for the reader. Readability aims to determine the strength of the text by considering the lengths of sentences and words of texts and the number of unknown words. The determination of the level of difficulty of the texts is intended to determine at what level the text is suitable for the reader, before the text reaches the reader.

The Human Rights, Citizenship and Democracy course is at the forefront of the courses that need to be read and understood. It is a requirement that values related to human rights, citizenship and democracy are introduced starting from early ages, with an independent course content. For this reason, the Board of Education and Discipline decision number 69 of June 25th, 2012, states that the "Human Rights, Citizenship and Democracy" course aims to teach the basic values about human rights, citizenship and democracy, besides the conceptual knowledge, to the students in the 4th grade of elementary education, starting from the 2015-2016 academic year. Another aim of the course is to ensure that students acquire this knowledge and values with regard to their lifestyle and culture. In this way, students will learn their rights and demand them when necessary, and will be able to make ethical assessments about them. Technical terms are intrinsicall to the texts of human rights, citizenship and democracy courses. This situation can make it difficult for the students to understand the texts in the textbook. Therefore, readability is of great importance when choosing books for this course.

Many studies about readibility and age level compliance (Kaya, 1998; Temur, 2002; Zorbaz, 2007; Köse, 2009; Çetinkaya, 2010; Geçit, 2010; Güven, 2010; Yürümez, 2010; Çeçen \& Aydemir, 2011; Karatay, Bolat \& Güngör, 2013; Okur \& Ar1, 2013; Baş \& Yıldız, 2015) have been conducted in Turkey. When the studies are examined, it is seen that no study was found about the readability and age level compliance of the Human Rights, Citizenship and Democracy textbook. In order to ensure that students benefit entirely from the course books, that have a special place among the educational tools, it is important that the level of readability matches the age level.

\section{Purpose}

The purpose of the study is to determine the readability and the age level compliance of the information texts in the 4th grade Human Rights, Citizenship and Democracy textbook. For this purpose, the following sub-problems have been addressed.

1. What are the readibility level and age level compliance of the texts in the 4th grade Human Rights, Citizenship and Democracy textbook according to the Flesch-Kincaid formula?

2. What are the readibility level and age level compliance of the texts in the 4th grade Human Rights, Citizenship and Democracy textbook according to the Gunning Fog Index formula?

3. What are the readibility level and age level compliance of the texts in the 4th grade Human Rights, Citizenship and Democracy course book according to the Ateşman formula?

4. What are the average readibility level and age level compliance of all the texts in the 4th grade Human Rights, Citizenship and Democracy textbook according to the Flesch-Kincaid, Gunning Fog Index and Ateşman formulas? 


\section{Method}

The document analysis technique was used as the data collection method in the study. Document analysis covers the analysis of materials that contain information about facts or phenomena intended to be investigated. In qualitative research, document analysis can be a stand-alone data collection method or can be used with other data collection methods (Yıldırım \& Şimşek, 2013). Descriptive and correlational analysis techniques were used during the data analyzing process. Mean scores and standard deviations were computed for each item. Also, frequencies and percentages were taken into account while examining the distribution of academic's participation in internationalization activities according to demographic variables. Finally, the prediction structure of academics' internationalization participation obtained from merged and separate groups of demographic variables were investigated by CHAID analysis.

\section{Findings}

In this research conducted to determine the readability and age level of the texts of the 4th grade Human Rights, Citizenship and Democracy textbook, the following results were obtained:

1. 4th grade Human Rights, Citizenship and Democracy textbook texts are very difficult and readability is in the 25-31 age range when analyzed according to the Flesch-Kincaid formula.

2. According to the Gunning Fog Index formula, the readability level is difficult.

3. According to the Ateşman formula, in terms of the readability level, the first text is very difficult, the second and the fourth texts are moderately difficult, and the third, fifth and sixth texts are difficult.

4. All of the texts of the course book are found difficult according to the average of the Felsch-Kincaid, Gunning

Fog Index and Ateşman formulas.

\section{Discussion and Conclusion}

According to the obtained data of the study, it can be said that, in the fourth grade primary school human rights, citizenship and democracy textbook, information texts' read ability level is difficult and they do not conform to the level of the 4th grade students. Research supporting these results has been conducted. For instance, Çiftçi, Çeçen and Melanlığlu (2007) reported that informative texts had lower readability scores than narrative texts in the study of Turkish textbooks in terms of readability using Ateşman's formula. The readability of a book depends on the reader's understanding of what the author wants to convey. Students understand short and simple sentences more easily than long, complicated sentences. In a similar study, Bağc1 and Ünal (2013) reached the conclusion that the readability of texts in textbooks is low.

One of the studies that revealed similar results to this research was done by Yürümez (2010). The aim of the study was to determine the readability and the age level compliance of the 9th grade biology textbook prepared by the Ministry of National Education. The Flesch-Kincaid and Gunning Fog Index formulas were studied with various texts and it was found that the book has a hard-to-understand language and does not fit the target age. In a similar study, Güven (2010) researched the read ability and the age level compliance of the 6th grade science and technology textbook. The textbook was examined according to the Flesch-Kincaid, Gunning Fog Index, Cloze Test and Sonmez formulas and, according to the Flesch-Kincaid and Gunning Fog Index formulas, the course book was found to be difficult to understand. Karatay, Bolat \& Güngör (2013) studied the readability and understandability of the texts taken from Turkish textbooks according to expert opinion and the extractive readability process. According to the readability formulas, including Flesch-Kincaid, Gunning Fog Index and Atesman, it was concluded that texts in Turkish textbooks are generally difficult. The readability level of a book depends on its length, the shortness of the sentences, the complexity or the simplicity of the words used (Soyibo, 1996). When the research studies are examined, it can be said that the textbooks which are intended to be taught in the schools are prepared without taking important features into consideration, such as the age and the reading levels of the students.

In the light of the results obtained in the research, the following suggestions can be made; 
The basis of the learning-teaching process is the student's perception and internalization of the course. One of the important factors is the understanding of the books as course materials. For this purpose, texts in course books should be organized according to the characteristics of the target group.

The preparation of course books according to the age and level of the students is important in terms of intelligibility. For this reason, the readability levels of the texts in prepared books should be investigated before the books start to be used. 


\section{Kaynakça / References}

Altay, N., Ay, S, Ertek, Z.Ö., Polat, H., Selmanoğlu, E., \& Yalçın, H. (2017). İlkokul insan hakları, yurttaşlık ve demokrasi ders kitabı 4.(1.Baskı). Ankara: Milli Eğitim Bakanlığı.

Ateşman, E. (1997). Türkçede okunabilirliğin ölçülmesi. Ankara Üniversitesi TÖMER Dil Dergisi, 58, 171-174.

Bağcı, H. ve Ünal, Y. (2013). İlköğretim 8. sınıf türkçe ders kitaplarındaki metinlerin okunabilirlik düzeyi. Ana Dili Ë̆itimi Dergisi, 1(3), 12-28.

Baş, B. \& Yıldız, F., İ. (2015). 2. sınıf türkçe ders kitabındaki metinlerin okunabilirlik açısından incelenmesi. Mersin Üniversitesi Eğitim Fakültesi Dergisi, 11 (1), 52-61.

Çetinkaya, G. (2010). Türkçe metinlerin okunabilirlik düzeylerinin tanımlanması ve sinıflandırılması (Yayımlanmamış Doktora Tezi). Ankara Üniversitesi, Sosyal Bilimler Enstitüsü, Ankara.

Çeçen, M. A. \& Aydemir, F. (2011). Okul öncesi hikâye kitaplarının okunabilirlik açısından incelenmesi. Mustafa Kemal Üniversitesi Sosyal Bilimler Enstitüsü Dergisi, 16, 185-194.

Çiftçi, Ö., Çeçen, M. A. \& Melanlıŏ̆lu, D. (2007). Altıncı sınıf Türkçe ders kitaplarındaki metinlerin okunabilirlik açısından değerlendirilmesi. Elektronik Sosyal Bilimler Dergisi, 6(22), 206-219.

Geçit, Y. (2010). Lise Coğrafya 9 ve lise Coğrafya 11 ders kitaplarının bazı okunabilirlik formülleri ile değerlendirilmesi. Kuram ve Uygulamada Eğitim Bilimleri, 10(4), 2177-2220

Güven, S.(2010). İlköğretim 6. Sınıf Fen ve Teknoloji Ders Kitabının Okunabilirliği ve Hedef Yaş Düzeyine Uygunluğu. Yüksek Lisans Tezi. Selçuk Üniversitesi, Konya.

Kaya, Z. (1998). Gs Eğitimi Kitaplarının Okunaklılığı. Eğitim ve Bilim. 108: 30-35.

Karatay, H., Bolat, K. K. ve Güngör, H. (2013). Türkçe ders kitaplarındaki metinlerin okunabilirlik ve anlaş1labilirliği. International Journal of Social Science, 6(6), 603-623.

Köse, Ö., E. (2009). Biyoloji 9 ders kitabında hücre ile ilgili metinlerin okunabilirlik düzeyleri. Çankaya Üniversitesi Fen-Edebiyat Fakültesi, 12, 141-150.

Millî Eğitim Bakanlığı Ders Kitapları ve Eğitim Araçları Yönetmeliği (2012). 28409 Sayılı yönetmelik (http://www.resmigazete.gov.tr/eskiler/2012/09/20120912-2.htm) adresinden 28.02.2018 tarihinde erişilmiştir.

Okur, A. \& Arı, G. (2013). 6, 7, 8. sınıf Türkçe ders kitaplarındaki metinlerin okunabilirliği. İlköğretim Online, 12(1), 202-226.

Sever, S. (2003). Çocuk ve edebiyat. Ankara: Kök Yayıncılık.

Soyibo, K. (1996). A comparison of communication strategies among three caribbean higy school biology textbooks. Journal of Biological Education, 30(3), 190-194.

Temur, T. (2002). İlköğretim 5.Sınıf Türkçe Ders Kitaplarında Bulunan Metinler ile Öğrenci Kompozisyonlarının Okunabilirlik Düzeyleri Açısından Karsılaştırılması. (Yayımlanmamış yüksek lisans tezi). Gazi Üniversitesi, Eğitim Bilimleri Enstitüsü, Ankara: Türkiye.

Yıldırım, A. \& Şimşek, H. (2016). Sosyal bilimlerde nitel araştırma yöntemleri (10. Baskı). Ankara: Seçkin Yayınc1lik.

Yürümez, B. (2010). Ortaöğretim 9. sınıf biyoloji ders kitabının okunabilirliği ve hedef yaş düzeyine uygunluğu (Yayımlanmamış yüksek lisans tezi). Selçuk Üniversitesi, Konya.

Zorbaz, K. Z. (2007). Türkçe ders kitaplarındaki masalların kelime-cümle uzunlukları ve okunabilirlik düzeyleri üzerine bir değerlendirme. Eğitimde Kuram ve Uygulama, 3 (1), 87-101. 